\title{
Kajian Algoritma Deteksi Hama Gudang Menggunakan Metode Pengukuran Intensitas Pantulan Cahaya Objek
}

\author{
Rida Hudaya1, Slamet Budiawan², Wawan Sutian², Mazdani Ulfah Daulay², \\ Salbiah $^{2}$, M. Achrom², Abdurakhman², Budhi Suherman'2, Hendra Adi Prasetia ${ }^{2}$, Mustopha \\ Ahad $^{2}$, Alli Nur Magribi', Ferly Fernando NA ${ }^{3}$, \\ M. Ferdyansyah Kusumah ${ }^{3}$ \\ ${ }^{1}$ Jurusan Teknik Elektro, Politeknik Negeri Bandung, Indonesia 40012 \\ E-mail : rida_hudaya@polban.ac.id \\ ${ }^{2}$ Balai Uji Terap Teknik dan Metode Karantina Pertanian, Kementrian Pertanian, Indonesia 17320 \\ E-mail : sbudiawangm@gmail.com \\ ${ }^{3}$ Agro-Technology Division, eFarming Corpora Community, Indonesia 40194 \\ E-mail : edufarmcorpora@gmail.com
}

\begin{abstract}
ABSTRAK
Proses pemeriksaan komoditas pertanian yang cepat dan akurat di pintu masuk dan keluar pelabuhan dan bandara oleh Petugas Karantina merupakan tuntutan pelayanan yang harus dilaksanakan. Hal ini dilakukan agar tidak menimbulkan kerugian dan biaya tinggi dalam penanganan pengiriman dan penerimaan komoditas pertanian. Salah satu proses pemeriksaan yang dilaksanakan adalah mendeteksi keberadaan serangga hama dalam suatu komoditas pertanian. Proses pemeriksaan ini dapat dilakukan dengan cara menggunakan detektor elektronik. Masalah penelitian yang dikemukakan dalam makalah ini adalah kajian algoritma pengolahan data intensitas objek yang berasal dari detektor elektronik. Objek penelitian yang digunakan dalam pemeriksaan ini adalah keberadaan serangga Araecerus fasciculatus (Coleoptera: Anthribidae) dalam gudang biji kopi. Metode yang digunakan adalah mengukur nilai intensitas berkas cahaya yang dipantulkan dari objek serangga dan objek biji kopi melalui detektor elektronik secara langsung dan realtime tanpa merusak objek yang diperiksa. Data intensitas objek diolah oleh unit mikrokontroler dan data yang diterima kemudian dibandingkan satu dengan lainnya. Jika terjadi perbedaan, maka dapat dipastikan adanya objek serangga dalam gudang biji kopi. Hasil pengujian menunjukan bahwa algoritma yang dikembangkan mampu mengolah data intensitas cahaya yang dipantulkan secara real-time dan mampu mendeteksi keberadaan objek serangga yang terdapat pada gudang biji kopi secara cepat dan tepat.
\end{abstract}

Kata Kunci

Biji kopi, objek serangga, serangga hama gudang, araecerus fasciculatus, detektor elektronik,intensitas objek

\section{PENDAHULUAN}

\subsection{Peluang masuknya OTP}

Indonesia merupakan negara mega biodiversity dunia dengan keragaman spesies flora dan fauna yang sangat tinggi. Disamping itu kemajuan di bidang perdagangan dunia semakin berkembang dalam era globalisasi dengan disetujuinya General Agreements on Trade and Tariff (GATT) di Marrakesh, Maroko pada tanggal 15 April 1994 yang diikuti dengan pembentukan World Trade Organization (WTO) pada tanggal 1 Januari 1995. Blok ekonomi juga semakin berkembang seperti European Union (EEC), Arab Common Market (ACM), Asean Free Trade Area (AFTA), Latin American Free Trade Association (LAFTA), dan North American Free Trade Area (NAFTA). Perkembangan ini membuka peluang masuknya beberapa organisme pengganggu tumbuhan (OPT) yang menyertai komoditas pertanian.

Badan Karantina bertugas menjaga wilayah Indonesia dari masuknya OPT, mengidentifikasi dan memprediksi resiko yang diakibatkannya. Hasil identifikasi OPT dan perkiraan resikonya tersebut dijadikan dasar untuk mencegah masuknya OPT berbahaya ke suatu wilayah bedasarkan pada bukti ilmiah [1][2][3]. Hasil pengujian di Tenggara Nigeria pernah dilakukan tehadap pola penyebaran Araecerus fasciculatus. Hasilnya tergantung pada kecepatan pengeringan komoditas [4][5][6][7]. Tindakan karantina dilakukan dengan penuh kecermatan dan kewaspadaan. Dalam makalah ini pembahasan akan dibatasi pada tindakan lingkup tugas pemeriksaan.

Pemeriksaan terhadap serangga hama gudang dalam komoditas pertanian di pintu pemasukkan dan pengeluaran oleh Petugas Karantina Pertanian dituntut untuk cepat dan akurat. Hal ini agar tidak menimbulkan kerugian dan biaya tinggi dalam penanganan pengiriman komoditas pertanian. Untuk mengetahui adanya serangga hama gudang sasaran dapat dilakukan dengan cara memeriksa secara manual langsung. Namun kecilnya ukuran hama gudang menimbulkan kesulitan dalam pemeriksaan di lapangan. Untuk mempermudah proses pemeriksaan komoditas pertanian yang akan dilalu-lintaskan dan untuk meyakinkan bahwa komoditas telah bebas dari adanya serangga 
hidup maka perlu alat untuk mendeteksi serangga sasaran dengan mengguakan detektor elektronik.

\subsection{Komoditas Kopi}

Indonesia adalah negara penghasil kopi terbesar di dunia setelah Brazil, Vietnam, dan Kolombia. Data Kementerian Pertanian pada 2018, produksi kopi Indonesia mencapai 674.636 ton dimana $97 \%$ di ekspor dalam bentuk biji kopi hijau yang masih mentah dan hanya 3\% yang diekspor dalam bentuk kopi olahan [8][9][10]. Publikasi Badan Pusat Statistik (BPS), mengenai volume ekspor kopi hingga Juli 2020 mencapai 186,8 ribu ton. Jumlah tersebut naik $10,69 \%$ dibandingkan tahun sebelumnya pada periode yang sama. Namun, nilai ekspornya justru turun 8,01\%. Ekspor kopi Indonesia terbesar pada tahun 2020 yakni ke Jepang, Hongkong, Korea Selatan, Taiwan dan Cina [11][12]. Alasan inilah mengapa komoditas pertanian kopi dijadikan objek kajian.

\subsection{Serangga Hama Gudang}

Potensi ekspor kopi membutuhkan sistem penggudangan yang akan mengundang munculnya serangga hama gudang yang sangat merugikan. Salah satu serangga hama gudang yang paling sering ditemukan adalah Araecerus fasciculatus (De Geer, 1775) (Coleoptera: Anthribidae). Berbagai usaha untuk mengendalikan serangga ini telah diteliti. Serangga hama gudang ini merupakan hama penting pada produk simpanan seperti biji-bijian, biji kopi, singkong, dan bahan obat tradisional China. Serangga ini dapat menyebabkan kerugian besar. Sehingga perangkap lapangan 2-feniletanol dan 2-feniletil asetat digunakan untuk menarik serangga tersebut [13]. Penggunaan aggregation pheromone dalam bentuk squalene, 2,6,10,15,19,23-hexamethyl-2,6,10,14 , 18,22tetracosahexaene, terbukti mampu menarik serangga jantan dan betina dalam Y-tube olfactometer [14]. Studi lain untuk menurunkan serangan serangga hama adalah melalui sanitasi lingkungan [15].

\subsection{Detektor Elektronik}

Selain penggunaan sistem biologi, kimia maupun fisis untuk memantau keberadaan serangga hama gudang, berbagai studi yang berkaitan dengan penggunaan sistem elektronik juga telah dilakukan. Penggunaan modul kamera terintegrasi dalam jaringan sensor nirkabel bersamaan dengan perangkap kertas lengket dan pengukuran suhu, kelembapan, dan tingkat intensitas cahaya dalam rumah kaca. Algoritme pemrosesan gambar diterapkan untuk mendeteksi dan menghitung secara otomatis hama serangga pada perangkap lengket serangga dengan akurasi deteksi temporal rata-rata $93 \%$ dibandingkan dengan penghitungan manual [16][17]. Selain itu, penggunaan machine learning terhadap objek hitam putih khususnya lalat putih dan lalat buah diperoleh akurasi rata-rata 98\% dan waktu komputasi 8-9 detik per citra [18]. Penggunaan cascaded convolutional neural networks (CNN) menghasilkan akurasi pencacahan 88$95 \%$, sedangkan pengklasifikasi serangga multi-class memiliki akurasi $86-92 \%$ dengan waktu pemrosesan rata-rata 13-15 detik dan 2-3 detik [19]. Penggunaan teknologi GIS juga dapat mengurangi perkembangan serangga hama [20].

Penggunaan perangkat yang lebih kompleks dilakukan dengan micro-computerized tomography (micro-CT) scans untuk melakukan pengamatan keberadaan serangga hama gudang [21]. Untuk pengendalian selektif Sitophilus, telah digunakan pirimiphos-metil dosis rendah [22]. Teknik spektroskopi dan pencitraan, seperti fluoresensi light detection and range (LIDAR) serta spektroskopi Vis/NIR digunakan untuk menentukan sifat spektral hama. Teknik-teknik ini terbukti menjadi metode yang dapat diandalkan untuk pemantauan yang lebih baik terhadap pergerakan serangga hama [23].

\section{METODE PENELITIAN}

\subsection{Piksel}

Metode algoritma yang akan dijelaskan meliputi pengolahan data intensitas piksel dari tiga jenis citra yaitu citra komoditas biji kopi, citra serangga hama gudang dan citra piksel detektor. Piksel adalah satuan terkecil dari sebuah citra. Satu piksel dapat memiliki tiga jenis variabel yaitu variabel $P_{r}$, variabel $P_{g}$ dan variable $\mathrm{P}_{\mathrm{b}}$, seperti dijelaskan pada Gambar 1(a). Piksel dapat direpresentasikan sebagai sebuah matrik yang terdiri dari variabel $P_{x, y, r}$, variabel $P_{x, y, g}$ dan variable $\mathrm{P}_{\mathrm{x}, \mathrm{y}, \mathrm{b}}$, seperti dinyatakan dalam Persamaan (1), dimana sebuah piksel selain menunjukkan nilai intensitas, juga memiliki nilai posisi dalam sebuah citra.

$$
P_{x, y, r, g, b}=\left[P_{x, y, r}, P_{x, y, g}, P_{x, y, b}\right]
$$

yang mana:

- $\mathrm{P}_{\mathrm{x}, \mathrm{y}}$ adalah koordinat piksel dalam sebuah citra

$-0 \leq P_{r} \leq 255$

$-0 \leq P_{g} \leq 255$

$-0 \leq P_{b} \leq 255$

\subsection{Citra Serangga dan Biji kopi}

Sebuah citra C dapat dibentuk dari beberapa piksel. Sehingga citra $\mathrm{C}$ dapat direpresentasikan sebagai tiga buah lapisan matrik yang terdiri dari lapisan matrik $\mathrm{R}$, lapisan matrik $\mathrm{G}$ dan lapisan matrik B. Lapisan matrik $\mathrm{R}$ dibangun dari beberapa piksel $R$, lapisan matrik $G$ dibangun dari beberapa piksel $G$ dan lapisan matrik $B$ dibangun dari beberapa piksel $\mathrm{B}$, seperti dijelaskan dalam Gambar 1(b). 


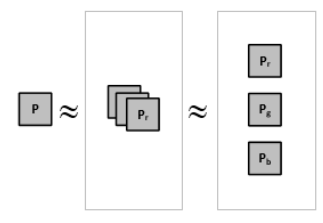

(a)

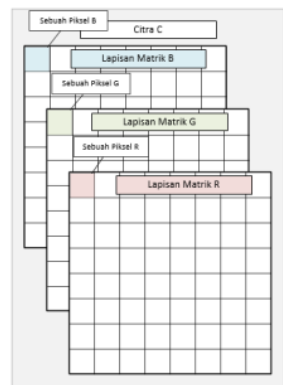

(b)
Gambar 1. Representasi citra dalam lapisan matrik R,G,B

(a) Representasi sebuah piksel

(b) Lapisan matrik R,G,B dalam sebuah citra

Berdasarkan penjelasan diatas maka sebuah citra serangga hama gudang dapat direpresentasikan sebagai sebuah matrik $\mathrm{C}_{\text {serangga }}$ yang menempati atau menutupi beberapa piksel citra. Sebuah serangga hama gudang dapat menempati beberapa piksel. Sehingga ukuran serangga hama gudang dapat memiliki ukuran beberapa piksel dengan ukuran luas piksel yang bervariasi. seperti yang dijelaskan dalam Gambar 2(a). Demikian juga sebuah citra komoditas biji kopi dengan cara yang sama dapat direpresentasikan sebagai sebuah matriks $\mathrm{C}_{\text {biji-kopi }}$ yang menempati atau menutupi beberapa piksel citra.biji

$$
C_{\text {serangga }(x, y, r, g, b)}=\left[\begin{array}{l}
C_{\text {serangga }(x, y, r),} \\
C_{\text {serangga }(x, y, g)} \\
C_{\text {serangga }(x, y, b)}
\end{array}\right]
$$

yang mana:

- $C_{\text {serangga(x,y) }}$ adalah koordinat piksel dalam sebuah bingkai citra

$-0 \leq C_{\text {serangga(r) }} \leq 255$

$-0 \leq C_{\text {serangga }(g)} \leq 255$

$-0 \leq C_{\text {serangga }(b)} \leq 255$

$$
C_{b i j i-k o p i(x, y, r, g, b)}=\left[\begin{array}{l}
C_{b i j i-k o p i(x, y, r)}, \\
C_{b i j i-k o p i(x, y, g)} \\
C_{b i j i-k o p i(x, y, b)}
\end{array}\right]
$$

yang mana:

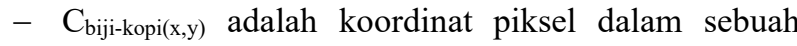
bingkai citra

$-0 \leq C_{\text {biji-kopi(r) }} \leq 255$

$-0 \leq C_{\text {biji-kopi(g) }} \leq 255$

$-0 \leq C_{\text {biji-kopi(b) }} \leq 255$

Dalam kondisi tertentu objek citra serangga hama gudang dan komoditas biji kopi dapat bertumpang tindih satu sama yang lainnya seperti pada Gambar 2(b) dimana serangga hama gudang berada diatas komoditas biji kopi dan dibagian lain serangga hama gudang berada dibawah komoditas biji kopi.

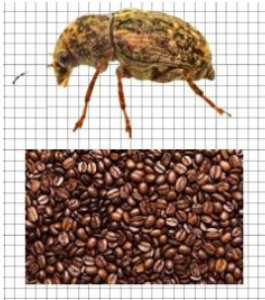

(a)

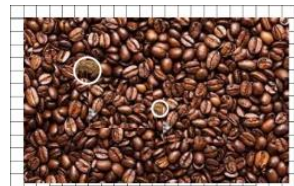

(b)
Gambar 2.Cakupan piksel serangga relatif terhadap biji kopi

(a) Ilustrasi cakupan piksel dari sebuah citra serangga dan biji kopi

(b) Berbagai kemungkinan posisi serangga hama gudang terhadap komoditas biji kopi

Sebuah atau beberapa serangga hama gudang dapat berukuran beberapa piksel dengan ukuran piksel yang bervariasi. Sehingga hama gudang serangga dapat menutupi berbagai ukuran luasan beberapa piksel citra, seperti yang dijelaskan dalam Gambar 3.

Pada Gambar 2(b) objek serangga hama gudang baik yang diatas maupun yang dibawah komoditas biji kopi tidak dapat dilihat dengan jelas oleh mata telanjang.Oleh karena itu diperlukan alat bantu. Salah satunya adalah detektor elektronik. Apabila piksel $\mathrm{P}$ pada Gambar 1(a) yang terdiri dari piksel $\mathrm{P}_{\mathrm{r}}, \mathrm{P}_{\mathrm{g}}$ dan $\mathrm{P}_{\mathrm{b}}$ merupakan representasi dari piksel detektor maka Persamaan (1) dapat dinyatakan dengan cara lain seperti pada Persamaan (4). Hal ini terjadi karena posisi piksel detektor dibuat tetap dan dapat ditempatkan dimana saja dalam bingkai objek citra yang diperiksa.

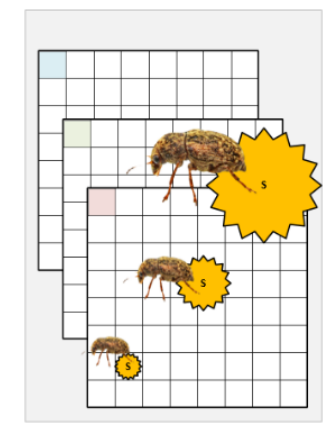

Gambar 3. Ilustrasi cakupan piksel dari sebuah citra serangga dan biji kopi

$$
P_{r, g, b}=\left[P_{r}, P_{g}, P_{b}\right]
$$

yang mana:

$-0 \leq P_{r} \leq 255$

- $0 \leq P_{g} \leq 255$

- $0 \leq P_{b} \leq 255$ 


\section{HASIL DAN PEMBAHASAN}

Diagram sistem kerja detektor pada Gambar 4(a) terdiri dari mikrokontroler tempat dimana perangkat lunak ditanam yang bekerja menjalankan algoritma perhitungan intensitas berkas cahaya. Flash memory membantu dan menyimpan proses perhitungan dan tampilan grafik. Layar monitor berfungsi untuk menampilkan hasil. Sedangkan 3-channel RGB Detector berfungsi mendeteksi komponen RGB dari citra objek.

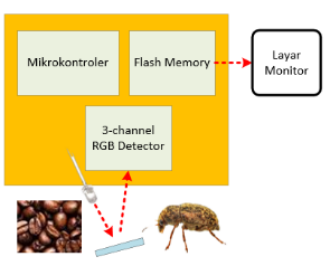

(a)

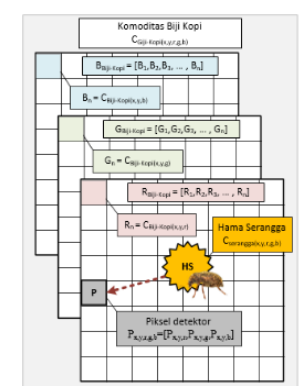

(b)
Gambar 4.Diagram blok sistem detektor dan algoritma Proses

(a) Diagram blok sistem kerja detektor

(b) Diagram algoritma representasi sistem detektor

Algoritma untuk penyelesaian deteksi serangga hama gudang pada komoditas kopi dilakukan dengan ilustrasi konsep yang dijelaskan pada Gambar 4(b). Serangga hama gudang yang direpresentasikan dengan Persamaan (2) terdiri dari komposisi nilai intensitas dari berkas cahaya r,g dan b. Persamaan (2) akan menjadi sederhana dengan penggunaan berkas cahaya $r$, g dan $b$ melalui penggunaan detektor elektronik yang diposisikan secara tetap dimana saja diseluruh permukaan objek komoditas kopi objek periksa. Sehingga Persamaan (2) dapat dinyatakan sebagai Persamaan (5) untuk berkas cahaya r, Persamaan (6) untuk berkas cahaya g dan Persamaan (7) untuk berkas cahaya $b$.

$$
\begin{aligned}
& R_{\text {serangga }(r)}=C_{\text {serangga }(r)} \\
& G_{\text {serangga }(g)}=C_{\text {serangga }(g)} \\
& B_{\text {serangga }(b)}=C_{\text {serangga }(b)}
\end{aligned}
$$

yang mana:

- $R_{\text {serangga(r) }}$ adalah nilai intensitas berkas cahaya $r$.

- $\mathrm{G}_{\text {serangga(g) }}$ adalah nilai intensitas berkas cahaya g.

- $B_{\text {serangga(br) }}$ adalah nilai intensitas berkas cahaya $b$.

Komoditas kopi yang direpresentasikan dengan Persamaan (3) terdiri dari matrik lapisan $R_{n}$, matrik lapisan $G_{n}$ dan matrik lapisan $B_{n}$ dapat dinyatakan sebagai Persamaan (8) untuk matrik lapisan R , Persamaan (9) untuk matrik lapisan G dan Persamaan (10) untuk matrik lapisan B.

$$
\begin{aligned}
& \mathrm{R}_{\text {biji-kopi(n) }}=\mathrm{C}_{\text {biji-kopi(x,y,r) }} \\
& \mathrm{G}_{\text {biji-kopi(n) }}=C_{\text {biji-kopi }(\mathrm{x}, \mathrm{y}, \mathrm{g})}
\end{aligned}
$$

$$
\mathrm{B}_{\mathrm{biji}-\mathrm{kopi}(\mathrm{n})}=\mathrm{C}_{\mathrm{biji}-\mathrm{kopi}(\mathrm{x}, \mathrm{y}, \mathrm{b})}
$$

yang mana:

- $\mathrm{R}_{\text {biji-kopi(n) }}$ adalah matrik nilai intensitas lapisan $\mathrm{R}$.

- $\mathrm{G}_{\text {biji-kopi(n) }}$ adalah matrik nilai intensitas lapisan G.

- $B_{\text {biji-kopi(n) }}$ adalah matrik nilai intensitas lapisan B.

- $\mathrm{C}_{\text {biji-kopi(x,y) }}$ adalah koordinat piksel dalam sebuah bingkai citra.

- $\mathrm{C}_{\text {biji-kopi(r) }}$ adalah nilai intensitas $\mathrm{r}$ suatu piksel pada koordinat tertentu.

- $\mathrm{C}_{\text {biji-kopi(g) }}$ adalah nilai intensitas g suatu piksel pada koordinat tertentu.

- $\mathrm{C}_{\text {biji-kopi(b) }}$ adalah nilai intensitas b suatu piksel pada koordinat tertentu.

Piksel detektor yang direpresentasikan dengan Persamaan (4) terdiri dari komposisi nilai intensitas dari berkas cahaya $r$, g dan $b$, dapat dinyatakan menjadi Persamaan (11) untuk berkas cahaya r, Persamaan (12) untuk berkas cahaya g dan Persamaan (13) untuk berkas cahaya b.

$$
\begin{aligned}
& \mathrm{R}_{\text {detektor(r) }}=\mathrm{P}_{\mathrm{r}} \\
& \mathrm{G}_{\text {detektor(g) }}=\mathrm{P}_{\mathrm{g}} \\
& \mathrm{B}_{\text {detektor(b) }}=\mathrm{P}_{\mathrm{b}}
\end{aligned}
$$

yang mana:

- $R_{\text {detektor(r) }}$ adalah nilai intensitas berkas cahaya $r$.

- $\mathrm{G}_{\text {detektor(g) }}$ adalah nilai intensitas berkas cahaya $\mathrm{g}$.

- $B_{\text {detektor(b) }}$ adalah nilai intensitas berkas cahaya b.

Untuk posisi piksel dibawah berkas cahaya detektor, maka Persamaan (8), Persamaan (5) dan Persamaan (11) terdapat pada posisi yang sama. Demikian juga untuk Persamaan (9), Persamaan (6) dan Persamaan (12), Hal yang sama terjadi pada Persamaan (9), Persamaan (7) dan Persamaan (13). Apabila $\mathrm{d}_{\mathrm{bij} \text {-kopi }}$ adalah jarak antara detektor dengan komoditas biji kopi dan $\mathrm{d}_{\text {serangga }}$ adalah jarak antara detektor dengan serangga hama, maka jarak $\mathrm{d}$ akan mempengaruhi hasil akhir nilai intensitas. Secara matematis dinyatakan dalam Persamaan (14)

$$
\begin{aligned}
& \mathrm{R}_{\text {detektor(r,g,b) }}=\mathrm{R}_{\text {biji-kopi(n) }} \\
& \text { bila } \mathrm{d}_{\text {biji-kopi }}<\mathrm{d}_{\text {serangga }} \\
& \mathrm{R}_{\text {detektor }(\mathrm{r}, \mathrm{g}, \mathrm{b})}=\mathrm{R}_{\text {serangga }(\mathrm{r}, \mathrm{g}, \mathrm{b})} \\
& \text { bila } \mathrm{d}_{\text {biji-kopi }}>\mathrm{d}_{\text {serangga }} \\
& \text { Intensitas Berkas Cahaya RGB }
\end{aligned}
$$

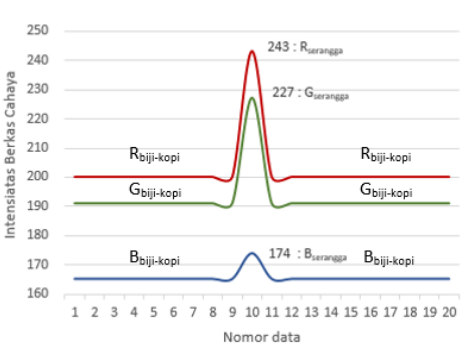

$$
\begin{aligned}
& \text { - }
\end{aligned}
$$

Gambar 5.Grafik sinyal pemantau detektor serangga hama gudang 
Tabel 1. Data pengukuran nilai intensitasl piksel.

\begin{tabular}{rccccccccc}
\hline \multirow{2}{*}{ No } & \multicolumn{3}{c}{ Objek Deteksi } & \multicolumn{3}{c}{ Detektor } & \multicolumn{3}{c}{ Selisih } \\
\cline { 2 - 11 } & $\mathbf{R}$ & $\mathbf{G}$ & $\mathbf{B}$ & $\mathbf{R}$ & $\mathbf{G}$ & $\mathbf{B}$ & $\mathbf{R} \mid$ & $\mathbf{| G |}$ & $|\mathbf{B}|$ \\
\hline 1 & 200 & 191 & 165 & 200 & 191 & 165 & 0 & 0 & 0 \\
\hline 2 & 200 & 191 & 165 & 200 & 191 & 165 & 0 & 0 & 0 \\
\hline 3 & 200 & 191 & 165 & 200 & 191 & 165 & 0 & 0 & 0 \\
\hline 4 & 200 & 191 & 165 & 200 & 191 & 165 & 0 & 0 & 0 \\
\hline 5 & 200 & 191 & 165 & 200 & 191 & 165 & 0 & 0 & 0 \\
\hline 6 & 200 & 191 & 165 & 200 & 191 & 165 & 0 & 0 & 0 \\
\hline 7 & 200 & 191 & 165 & 200 & 191 & 165 & 0 & 0 & 0 \\
\hline 8 & 200 & 191 & 165 & 200 & 191 & 165 & 0 & 0 & 0 \\
\hline 9 & 200 & 191 & 165 & 200 & 191 & 165 & 0 & 0 & 0 \\
\hline 10 & 243 & 227 & 174 & 243 & 227 & 174 & 0 & 0 & 0 \\
\hline 11 & 200 & 191 & 165 & 200 & 191 & 165 & 0 & 0 & 0 \\
\hline 12 & 200 & 191 & 165 & 200 & 191 & 165 & 0 & 0 & 0 \\
\hline 13 & 200 & 191 & 165 & 200 & 191 & 165 & 0 & 0 & 0 \\
\hline 14 & 200 & 191 & 165 & 200 & 191 & 165 & 0 & 0 & 0 \\
\hline 15 & 200 & 191 & 165 & 200 & 191 & 165 & 0 & 0 & 0 \\
\hline 16 & 200 & 191 & 165 & 200 & 191 & 165 & 0 & 0 & 0 \\
\hline 17 & 200 & 191 & 165 & 200 & 191 & 165 & 0 & 0 & 0 \\
\hline 18 & 200 & 191 & 165 & 200 & 191 & 165 & 0 & 0 & 0 \\
\hline 19 & 200 & 191 & 165 & 200 & 191 & 165 & 0 & 0 & 0 \\
\hline 20 & 200 & 191 & 165 & 200 & 191 & 165 & 0 & 0 & 0 \\
\hline
\end{tabular}

Hasil pemantau secara real-time diperlihatkan pada Gambar 5. Puncak grafik menunjukkan nilai intensitas dari $\mathrm{R}_{\text {detektor(r) }}, \mathrm{G}_{\text {detektor(g) }}$ dan $\mathrm{B}_{\text {detektor(b) }}$ yang nilainya sama dengan masing-masing nilai intensitas $R_{\text {serangga(r) }}$ $\mathrm{G}_{\text {serangga(g) }} \mathrm{B}_{\text {serangga(b). Sedangkan pada bagian grafik yang }}$ lain yang lebih datar menunjukkan nilai intensitas dari $\mathrm{R}_{\text {detektor(r) }}, \mathrm{G}_{\text {detektor(g) }}$ dan $\mathrm{B}_{\text {detektor(b) yang nilainya sama }}$ dengan masing-masing nilai intensitas $R_{\text {biji-kopi(r) }} G_{b i j i-}$ kopi(g) $B_{\text {biji-kopi(b). }}$

Terlihat jelas perbedaan antara komoditas yang terdapat serangga hama gudang dengan komoditas yang tanpa serangga hama gudang. Tabel 1 menunjukkan hasil pengukuran intensitas piksel. Algoritma yang diusulkan secara tepat dapat membedakan antara komoditas biji kopi dengan serangga hama gudang. Sehingga algoritma yang digunakan dalam metode ini dapat digunakan sebagai cara untuk mendeteksi serangga hama gudang. Tabel 1 juga menunjukkan hasil bahwa metode yang digunakan mampu secara cepat dan tepat mendeteksi keberadaan serangga hidup yang melewati sensor yang terdapat dalam gudang biji kopi.

\section{KESIMPULAN}

Algoritma yang dibangun pada metode yang digunakan dapat mendeteksi secara cepat dan tepat setiap serangga hama gudang yang melewati sensor dalam gudang komoditas biji kopi.

Penggunaan metode berkas cahaya RGB dapat menyederhanakan realisasi perangkat detektor hama gudang yang direpresentasikan dengan persamaanpersamaan matrik sederhana.

\section{UCAPAN TERIMA KASIH}

Penghargaan disampaikan kepada Politeknik Negeri Bandung yang telah memfasilitasi penulisan karya ilmiah ini melalui Surat Perjanjian Pelaksanaan Skema
Penelitian Mandiri

106.86/PL1.R7/PG.00.03/2021

Nomor:

Penghargaan yang sama disampaikan kepada Balai Uji Terap Teknik dan Metode Karantina Pertanian Badan Karatina Kementrian Pertanian Indonesia yang telah memberikan kesempatan bekerja bersama mengembangkan konsep dalam makalah ini.

\section{DAFTAR PUSTAKA}

[1] Badan Karantiina Indonesia, "Impor Tumbuhan dan Produk Tumbuhan," 2021 . https://karantina.pertanian.go.id/page-14-importumbuhan-dan-produk-tumbuhan.html (accessed May 10, 2021).

[2] Badan Karantina Indonesia, "Ekspor Tumbuhan dan Produk Tumbuhan,", 2021. https://karantina.pertanian.go.id/page-13-eksportumbuhan-dan-produk-tumbuhan.html (accessed May 10, 2021).

[3] Badan Karantina Indonesia, "Pedoman Pemanasan Sarang Burung Walet Untuk Pengeluaran ke Negara Republik Rakyat Tiongkok." Badan Karantina Indonesia, Jakarta Indonesia, 2014, [Online]. Available: https://bbkpsoetta.com/images/Karantina/perundangan/ KEPBARANTAN/SK_KaBarantan_2014_No_406.pdf.

[4] R.A. Plumbley and D. P. Rees, "An Infestation by Araecerus Fasciculatus (Degeer) (Coleoptera: Anthribidae) and Decadarchis Minuscula (Walsingham) (Lepidoptera: Tineidae) on Stored Fresh Yam Tubers in South-East Nigeria," Pergamon Press Ltd, vol. 19, no. 2, pp. 93-95, 1983.

[5] C. C. Childers and R. E. Woodruff, "A Bibliography of the Coffee Bean Weevil Araecerus fasciculatus (Coleoptera: Anthribidae)," Bull. Entomol. Soc. Am., vol. 26, no. 3, pp. 384-394, 1980, doi: 10.1093/besa/26.3.384.

[6] P. Rajamma and T. Premkumar, "Influence of moisture content/equilibrium relative humidity of cassava chips on the infestation by Araecerus fasciculatus DeGeer (Coleoptera: Anthribidae) and Rhyzopertha dominica (Fabricius) (Coleoptera: Bostrichidae)," Int. J. Pest Manag., vol. 40, no. 3, pp. 261-265, 1994, doi: $10.1080 / 09670879409371894$.

[7] A. G. Koval, K. V. Makarov, and B. A. Korotyaev, "On a Finding of the Polyphagous Pest, Coffee Bean Weevil Araecerus fasciculatus (DeG.) (Coleoptera, Anthribidae), in Natural Habitats of Different Regions of Southern Russia," Entomol. Rev., vol. 99, no. 1, pp. 129-132, 2019, doi: 10.1134/S0013873819010160.

[8] S. Almandasari, "Potensi Kopi Sebagai Komoditas Unggulan Indonesia," 2020. https://www.diassatria.com/potensi-kopi-sebagaikomoditas-unggulan-indonesia/\#: :text=Indonesia merupakan salah satu penghasil,kopi Indonesia mencapai 674.636 ton. (accessed May 20, 2021).

[9] I. K. Sari, "Potensi Kopi Indonesia," The Columnist, $2020 . \quad \mathrm{https}$ ///hecolumnist.id/artikel/potensi-kopiindonesia-1369\#: :text=Indonesia masuk dalam urutan keempat,yang menyumbangkan devisa cukup besar. (accessed May 10, 2021). 
[10] UKM Indonesia, "Potensi Ekspor Produk Kopi," UKM Indonesia. $\quad$ https://www.ukmindonesia.id/baca$\operatorname{artikel/286}$

[11] Lokadata, "Volume dan Nilai Ekspor Kopi, 2010-2020," Beritagar, 2020 https://lokadata.beritagar.id/chart/preview/volume-dannilai-ekspor-kopi-2010-2020-1603699853\#（accessed May 10, 2021)

[12] Badan Pusat Statistik Indonesia, "Statistik Kopi Indonesia 2018 - Badan Pusat Statistik," Badan Pusat Statistik Indonesia, 2019 https://www.bps.go.id/publication/download.html?nrbvf eve $=Y j$ VlMTYzNjIOYzIwODcwYmIzZDY0NDNh\&xz mn=aHR0cHM6Ly93d3cuYnBzLmdvLmlkL3B1Ymxp Y2F0aW9uLzIwMTkvMTIvMDYvYjVlMTYzNjIOYzI wODcwYmIzZDY0NDNhL3N0YXRpc3Rpay1rb3BpL WluZG9uZXNpYS0yMDE4Lmh0bWw\%3D\&twoadfno arfeauf=MjAyMS0wNS0xMCAwOTozMToyNw\%3D $\% 3 \mathrm{D}$ (accessed May 10, 2021).

[13] S. Yang et al., "Attraction of Coffee Bean Weevil, Araecerus fasciculatus, to Volatiles from the Industrial Yeast Kluyveromyces lactis," J. Chem. Ecol., vol. 43, no. 2, pp. 180-187, 2017, doi: 10.1007/s10886-0160809-5.

[14] S. Yang et al., "Male-Produced Aggregation Pheromone of Coffee Bean Weevil, Araecerus fasciculatus," $J$. Chem. Ecol., vol. 43, no. 10, pp. 978-985, 2017, doi: 10.1007/s10886-017-0894-0.

[15] W. R. Morrison, A. Bruce, R. V. Wilkins, C. E. Albin, and F. H. Arthur, "Sanitation improves stored product insect pest management," Insects, vol. 10, no. 3, pp. 120, 2019, doi: 10.3390/insects10030077.

[16] D. J. A. Rustia, C. E. Lin, J. Y. Chung, Y. J. Zhuang, J. C. Hsu, and T. Te Lin, "Application of an image and environmental sensor network for automated greenhouse insect pest monitoring," J. Asia. Pac. Entomol., vol. 23, no. $1, \quad$ pp. 17-28, 2020, doi: 10.1016/j.aspen.2019.11.006.

[17] M. Preti, F. Verheggen, and S. Angeli, "Insect pest monitoring with camera-equipped traps: strengths and limitations," J. Pest Sci. (2004)., vol. 94, no. 2, pp. 203 217, 2021, doi: 10.1007/s10340-020-01309-4.

[18] D. J. A. Rustia and T. Te Lin, "An IoT-based wireless imaging and sensor node system for remote greenhouse pest monitoring," Chem. Eng. Trans., vol. 58, no. October, pp. 601-606, 2017, doi: 10.3303/CET1758101.

[19] D. Jeric Arcega Rustia, C. Erh Lin, and T.-T. Lin, "A Real-time Multi-class Insect Pest Identification Method using Cascaded Convolutional Neural Networks Intelligent Integrated Pest Management System View project," Researchgate.Net, no. May, 2018, [Online]. Available:

https://www.researchgate.net/publication/333916287.

[20] L. Deleon, M. J. Brewer, I. L. Esquivel, and J. Halcomb, "Use of a geographic information system to produce pest monitoring maps for south Texas cotton and sorghum land managers," Crop Prot., vol. 101, pp. 50-57, 2017 , doi: 10.1016/j.cropro.2017.07.016.

[21] I. Alba-Alejandre, J. Alba-Tercedor, and F. E. Vega,
"Micro-CT to document the coffee bean weevil, araecerus fasciculatus (Coleoptera: Anthribidae), inside field-collected coffee berries (coffea canephora)," Insects, vol. 9, no. 3, 2018, doi: 10.3390/insects9030100.

[22] J. B. Johnson, "An overview of near-infrared spectroscopy (NIRS) for the detection of insect pests in stored grains," J. Stored Prod. Res., vol. 86, p. 101558, 2020, doi: 10.1016/j.jspr.2019.101558.

[23] M. N. Ahmad, A. R. M. Shariff, and R. Moslim, "Monitoring insect pest infestation via different spectroscopic techniques," Appl. Spectrosc. Rev., vol. 53, no. 10, pp. 836-853, 2018, doi: 10.1080/05704928.2018.1445094. 